\title{
AVALIAÇÃO DE PLANOS MUNICIPAIS DE EDUCAÇÃO: A EDUCAÇÃO INFANTIL EM QUESTÃO
}

\author{
EVALUATION OF MUNICIPAL EDUCATION PLANS: EARLY CHILDHOOD \\ EDUCATION IN QUESTION
}

\author{
Paulo Sérgio Garcia \\ Doutorado em Educação \\ pela Faculdade de Educação da Universidade de São Paulo - FEUSP \\ Coordenador do Observatório de Educação do Grande ABC - São Paulo \\ Professor do Programa de Pós-graduação em Educação da Universidade Municipal de São Caetano do Sul, USCS \\ paulo.garcia@online.uscs.edu.br \\ Nonato Assis de Miranda \\ Doutorado em Educação \\ pela Faculdade de Educação da Universidade Estadual de Caminas - Unicamp \\ Professor do Programa de PPGE e PPGA da Universidade Municipal de São Caetano do Sul, USCS \\ mirandanonato@uol.com.br
}

\begin{abstract}
Resumo: Neste estudo, realizamos uma avaliação dos Planos Municipais de Educação dos municípios do grande ABC, uma das regiões mais ricas do Brasil, para compreender como os municípios planejaram as melhorias para a Educação Infantil no contexto local. Trata-se de uma pesquisa qualitativa baseada na análise documental. Os documentos foram coletados nas secretarias de educação dos sete municípios, juntamente com as Leis que os aprovaram, e analisados a partir da análise de conteúdo. Os resultados mostraram similaridades e repetições nos textos, a partir do Plano Nacional de Educação, e superficialidade na maioria das estratégias inseridas nos planos dos municípios, carecendo de maiores especificidades, tal como prazo para a execução. As análises revelaram dois grupos de estratégias inseridas nos planos: no primeiro, aquelas alinhadas com as melhorias da Educação Infantil, como avanços na infraestrutura escolar, e, no segundo, outras voltadas para sua mercantilização, a promoção da regulação da oferta de ensino da educação básica pela iniciativa privada, a partir de parcerias público-privadas. Esses resultados poderão ser utilizados na formação de gestores e pelas Secretarias de Educação na implementação de políticas educacionais.
\end{abstract}

Palavras-chave: avaliação; educação infantil; planos municipais de educação; políticas públicas de educação; mercantilização.

\begin{abstract}
In this study we carried out an evaluation of the Municipal Education Plans of the Greater ABC municipalities, one of the richest regions in Brazil, to understand how the municipalities planned the improvements for Early Childhood Education in the local context. This is a qualitative research based on documentary analysis. The documents were collected in the departments of education of the seven municipalities, together with the laws that approved them, and analyzed using content analysis. The results showed similarities and repetitions in the texts, from the National Education Plan, and superficiality in most strategies inserted in the municipalities plans, lacking some specificities such as deadline for execution. The analyses revealed two groups of strategies included in the plans: in the first, those aligned with Early Childhood Education improvements, as advances in school infrastructure, and, in the second, others focused on its mercatilization, the promotion of the regulation of the offer of basic education by private initiative, from public-private partnerships. These results can be used in the principal's education and by the Departments of Education in the implementation of educational policies.
\end{abstract}

Keywords: evaluation; early childhood education; municipal education plans; public education policies; mercatilization.

Para citar - (ABNT NBR 6023:2018)

GARCIA, Paulo Sérgio; MIRANDA, Nonato Assis de. Avaliação de planos municipais de educação: a educação infantil em questão. Eccos - Revista Científica, São Paulo, n. 59, p. 1-21, e13577, out./dez. 2021. Disponível em: https://doi.org/10.5585/eccos.n59.13577. 


\section{Introdução}

A avaliação educacional tem ocupado um lugar privilegiado na educação internacional, em geral, e na brasileira, em particular. Trata-se de um assunto que tem sido associado a outros (avaliação e qualidade, avaliação e promoção, punição, entre outros) e se confunde com tantos outros (prova, medida, teste). O tema tem estado envolto em problematizações, questionamentos e incertezas e inserido em uma literatura repleta de elementos conceituais e de disputas de várias naturezas, sejam elas teóricas, metodológicas, ideológicas ou políticas.

A avaliação educacional pode ter como foco a aprendizagem dos alunos - avaliação da aprendizagem -, podendo ser interna, quando realizada em sala de aula tendo o professor como sujeito, ou externa, elaborada por agentes de fora da escola. As avaliações externas costumam, também, ser em larga escala pelo fato de abarcarem muitos alunos e muitas escolas. Há, ainda, a avaliação institucional, focando a instituição escolar como um todo, com o objetivo de verificar se a escola está cumprindo sua função social ou se seu Projeto Político-Pedagógico está atingindo as metas, e a avaliação de uma política, programa ou projeto, que pode ter como objetivo a busca de melhorias. Nosso estudo está inserido no campo da avaliação educacional, com foco em políticas educacionais. Neste sentido buscamos avaliar, após uma descrição detalhada, os Planos Municipais de Educação (PME) da região do Grande ABC, uma das áreas mais ricas do Brasil.

Os PME da região do Grande ABC foram elaborados a partir das indicações do Plano Nacional de Educação (PNE), que foi instituído pela Lei no 13.005/2014 (BRASIL, 2014). O PNE é um documento que visa a articulação de esforços, em regime de colaboração, para introduzir melhorias em toda a educação brasileira. Essa Lei, considerada uma política de estado, estabeleceu metas (20) e estratégias para uma política educacional de dez anos, com responsabilidades compartilhadas pela união, estados, distrito federal e municípios.

O PNE e os PME visam, entre outras questões, universalizar a oferta da etapa obrigatória da Educação Básica (de 04 a 17 anos), tornar maior o nível de escolaridade da população e a taxa de alfabetização, valorizar os profissionais da educação, diminuir as desigualdades sociais, aumentar os investimentos no campo educacional e trazer melhorias para a Educação Superior e Básica.

Nessa última questão, dentro da Educação Básica, a Educação Infantil, no Brasil, em geral, e na região do grande $\mathrm{ABC}$, em particular, carece de muitas melhorias, por exemplo, em relação à infraestrutura escolar (GARCIA; GARRIDO; MARCONI, 2017), à oferta de vagas e ao atendimento das crianças (CORRÊA, 2003), à formação de professores (KRAMER; 
NUNES; CORSINO, 2005; CAMPOS, 2008), à avaliação e ao monitoramento (BRASIL, 2006; 2009, DIDONET, 2012), entre outras.

Os PME da região do grande $\mathrm{ABC}$ se inserem nesse contexto de busca de melhorias por meio de metas e estratégias para 10 anos. É oportuno destacar que alguns estudos têm procurado investigar os PME dessa região, buscando compreender as influências sobre a elaboração dos documentos (GARCIA; BIZZO, 2018) e analisando a qualidade, a partir da meta 7 (GARCIA; MIRANDA, 2018a).

Neste estudo realizamos uma avaliação dos Planos Municipais de Educação dos municípios do grande $\mathrm{ABC}$, uma das regiões mais ricas do Brasil, para compreender como os municípios planejaram as melhorias para a Educação Infantil no contexto local.

\section{Avaliação de política pública: o Plano Nacional de Educação}

A avaliação é tida como um dos principais mecanismos de gestão de políticas públicas, pois possibilita informações sobre as metas, impactos, resultados, entre outros, dos programas e projetos criados pelo Estado. Ela pode ser descrita como:

[...] a análise crítica do programa (política) com o objetivo de apreender, principalmente, em que medida as metas estão sendo alcançadas, a que custo, quais os processos ou efeitos colaterais que estão sendo ativados (previstos ou não previstos, desejáveis ou não desejáveis) indicando novos cursos de ação mais eficazes (LIMA JR. et al., 1978, p. 4-5).

Embora existam diferenças nos modelos de avaliação, Mugnol e Gisi (2012) indicaram seis modelos de avaliações de políticas públicas. Entre eles, o modelo baseado em objetivos, em que tais objetivos se constituem em parâmetros para o trabalho de avaliação. Há também o modelo direcionado para a tomada de decisão, aquele denominado livre de objetivos ("goal free model'), transacional, entre outros.

Entre as metodologias usadas para avaliação de políticas estão a avaliação de metas, avaliação de impacto, de processos, de resultados, entre outras. Para Costa e Castanhar (2003, 979), a avaliação de metas visa verficar o "grau de êxito que um programa obtém com relação ao alcance de metas previamente estabelecidas". Para os autores, existem algumas limitações nesse processo, como: "dificuldade de especificar as metas de forma precisa; a existência de várias metas; a seleção de metas a serem incluídas no processo de avaliação; mudanças nas metas ao longo da própria execução do programa" (COSTA; CASTANHAR, 2003, p. 979).

Entre as políticas públicas educacionais, criadas a partir de metas, que geraram controvérsias, preocupações e expectativas, está o Plano Nacional de Educação, que visa 
articular as realidades do município, do estado e da união. Trata-se de um documento que se traduz como uma política educacional baseada em intenções para responder às demandas do país, em geral, e das cidades, em particular. Dessa forma, ele é constituído de estratégias de curto, médio e longo prazo.

O PNE sinalizou aos estados e aos municípios prazos (24/06/2015) para que esses finalizassem seus PME. Nesse contexto, as cidades da região do Grande ABC elaboraram seus documentos (primeiro semestre de 2015), considerando as características sociodemográficas próprias de cada realidade.

Garcia e Bizzo (2018) apreciaram o processo de elaboração Planos da região do Grande $\mathrm{ABC}$, a fim de compreender as influências realizadas por aqueles que lutavam pela laicidade dos documentos (movimento LGBT) e pela Igreja Católica, que pretendia remover dos textos os termos ideologia de gênero e diversidade. Em outro estudo, Garcia e Miranda (2018), nessa mesma região, analisaram como os municípios planejaram as melhorias na qualidade educacional a partir da análise da meta 7, da qualidade, demostrando que algumas estratégias estavam em consonância com os estudos de qualidade e outras, no entanto, mais alinhadas com o discurso neoliberal: alguma forma de privatização e a santificação da avaliação.

Esses estudos advogam que os PME se constituem em políticas educacionais com o intuito de melhorar a educação na região do grande $\mathrm{ABC}$ que, de fato, carece de melhorias, em geral, e na Educação Infantil, em particular. Melhorias, por exemplo, na infraestrutura, no atendimento as crianças, na formação de professores e na avaliação e no monitoramento, entre outras.

\section{Educação infantil: possibilidades de melhorias}

A Educação Infantil (EI) é caracterizada como a etapa inicial da educação básica e vem avançando nos últimos anos. Diversas legislações (Estatuto da Criança e do Adolescente; Lei de Diretrizes e Bases da Educação Nacional, entre outros) delinearam contornos buscando melhorias para a EI. Outros documentos, Política Nacional de Educação Infantil (BRASIL, 1994), Políticas de formação do profissional de Educação Infantil (BRASIL, 1994), buscaram atuar no mesmo sentido.

Em 1998, o MEC publicou o Referencial Curricular Nacional para a Educação Infantil (BRASIL, 1998); nos anos de 1990, as Diretrizes Nacionais Curriculares para a Educação Infantil (BRASIL, 1998); em 2006, os Parâmetros Nacionais de Qualidade para a Educação Infantil (BRASIL, 2006); em 2009, os Indicadores da Qualidade na Educação Infantil 
(BRASIL, 2009); em 2010, as Diretrizes Curriculares Nacionais para a Educação Infantil (BRASIL, 2010) e, em 2014, o PNE. Todas essas Leis também buscaram melhorar a qualidade da EI, todavia, não sem muitas controvérsias, críticas e discussões acaloradas sobre os temas.

Apesar desse conjunto de documentos ter auxiliado a pensar a qualidade, já que muitas ideias não foram implantadas, a EI ainda tem muito para avançar. Na infraestrutura, por exemplo, o Censo Escolar de 2020, da EI, mostrou que somente 28\% das escolas públicas (urbanas e rurais) possuíam biblioteca, $21 \%$ laboratório de informática, $6 \%$ de ciências, $26 \%$ quadra de esporte, $52 \%$ sala de professores.

Garcia, Guarrido e Marconi (2017), analisando a infraestrutura das escolas de Educação Infantil da região do grande $\mathrm{ABC}$, sinalizam que havia grande diversidade intra e extra municípios, e que as escolas, apesar de alguns avanços, ainda careciam de melhorias. Em relação à biblioteca, por exemplo, apenas São Bernardo do Campo possuía mais de $65 \%$ das instituições com tal espaço. Quanto ao laboratório de informática, somente Santo André e Diadema possuíam mais de $75 \%$ desses locais. Referente às quadras esportivas, fundamentais para a criação e organização de determinados tipos de ambientes e atividades escolares, os municípios não possuíam mais de $60 \%$ desses espaços.

Os mesmos autores indicaram que a infraestrutura escolar é fundamental, pois apoia e possibilita a criação e a organização de ambientes escolares de aprendizagem. Ou seja, sua ausência dificulta ou limita o desenvolvimento das crianças.

A EI necessita também avançar na oferta e no atendimento às crianças. Nesse sentido, Corrêa (2003), ao discutir as melhorias para este nível de ensino, utilizando o termo qualidade, afirmou que um dos principais fundamentos para tais avanços se relaciona à ideia de direitos da criança. Nesse contexto, a autora indica que o atendimento público se constitui no primeiro desafio da qualidade. Desta forma, "a defesa da ampliação de vagas é necessária, mas, também, a possibilidade de períodos de atendimento que sejam mais compatíveis com as necessidades de cada família" (CORRÊA, p. 96).

A formação de professores é outra área que a EI necessita avançar. Vários autores já realizaram reflexões sobre o tema (KRAMER; NUNES; CORSINO, 2005; CAMPOS, 2008). Campos (2008) sugere a construção de um novo perfil de professor adequado às escolas que recebem crianças pequenas. A autora indica que o papel da formação inicial e continuada necessita ser fomentado pela experiência vivida pelo profissional e que a formação pode desempenhar um papel decisivo na superação dessas deficiências da Educação Infantil.

No campo da formação continuada, Kramer, Nunes e Corsino (2005, p. 224) sinalizaram que ela se faz necessária não somente para "aprimorar a ação profissional ou melhorar a prática 
pedagógica. A formação é direito de todos os professores, é conquista e direito da população, por uma escola pública de qualidade".

A EI necessita avançar para superar outros desafios. Há, como descreveu Mantoan (2003), a questão da mudança das concepções dos professores em relação às crianças com algum tipo de deficiência, englobando o processo de ensino-aprendizagem, a melhoria nas condições e na formação do trabalho docente, entre outras. Existe também a questão de garantir a oferta do atendimento educacional especializado, complementar e suplementar, para as crianças com deficiência, transtornos globais do desenvolvimento e altas habilidades ou superdotação.

Outros avanços na EI podem ser realizados com o desenvolvimento de projetos pedagógicos e programas para auxiliar as comunidades no enfrentamento de problemas atrelados ao transporte escolar, à saúde, ao lazer das crianças, entre outros. De fato, como sinalizaram Dourado; Oliveira e Santos (2007) e Dourado e Oliveira (2009), o desenvolvimento da qualidade requer políticas públicas que assistam as comunidades locais.

Além dessas questões dos avanços em relação à EI, existem duas outras situações que necessitam ser acompanhadas "bem" de perto por aqueles que militam nesse nível de ensino. A primeira é a questão da avaliação e seus desdobramentos, e a segunda é a possibilidade da regulação da EI ser realizada pela iniciativa privada.

No primeiro caso, a avaliação da EI vem sendo realizada sobre dimensões relacionadas ao planejamento institucional, à multiplicidade de experiências e linguagens, às interações, à promoção da saúde, à infraestrutura, à formação e às condições de trabalho das professoras e demais profissionais da educação (BRASIL, 2010), entre outras questões.

A avaliação e o monitoramento, na EI, possuem, nesse cenário, caráter contextual. Sendo assim, essas questões contextuais se afastam das formas de avaliação que são utilizadas no Ensino Fundamental e Médio, ou seja, atreladas aos resultados dos alunos.

Tal questão, a diferença nas formas de avaliação, necessita estar bem situada, pois em 2011, segundo DIDONET (2012), começou, no Brasil, um debate para validar a avaliação do desenvolvimento infantil, em creches, a partir do uso de um instrumento norte-americano (ASQ-3 - Ages, Stages Questionnaires, Third Edition), que foi utilizado e validado nas escolas públicas do Rio de Janeiro. Todavia, houve grande contestação por parte de pesquisadores, professores e entidades que expressaram repúdio a essa forma de avaliação que se distanciava das diretrizes já instituídas na política nacional de Educação Infantil.

Em dezembro de 2011, foi criado pelo MEC, por meio da Portaria $n^{\circ} 1.747$, um Grupo de Trabalho para elaborar subsídios para uma efetiva política de avaliação da EI no Brasil. Em 
2012, a Portaria $\mathrm{n}^{\mathbf{0}} 379$ instituiu os representantes dos órgãos e das entidades para esse grupo (Grupo de Trabalho de Avaliação da Educação Infantil). A tarefa central era criar um marco de referência, estabelecendo diretrizes e metodologias para subsidiar um programa de avaliação.

As indicações desse grupo foram, por um lado, no sentido de que a aprendizagem e o desenvolvimento das crianças devem ocorrer nos termos do art. 31 da LDBEN/96, com o uso de observações e de registros contextualizados associados à escrita, à gravação de falas, aos diálogos, às imagens e vídeos, entre outros. Por outro, não cabe, na EI, a introdução da cultura do teste como referencial da qualidade, pois são danosos para as crianças.

De fato, os resultados das avaliações em larga escala têm construído uma cultura que cria tensão nos gestores, professores, alunos e comunidade; superficializa os conteúdos e as habilidades, não incidindo sobre valores, nem sobre atitudes, capacidade de persistência e de esforço e nem sobre a alegria da descoberta. Indica-se, ainda, que ela privilegia a memória de informações, classifica, quantifica, compara a partir de padrões, induz o treinamento dos alunos para as provas, institui os processos de meritocracia, competição e rankings, deslocando o foco do ensino e da aprendizagem no conhecimento para o reconhecimento e, como sinalizou Hagopian (2014), geram um grande mercado de consumo da educação.

Todavia, Didonet (2012) indicou que a Educação Infantil não está imune a essa avalanche de avaliações presentes na educação brasileira. Até o presente momento, novembro de 2021, a EI não foi invadida por essa cultura, apesar de ela estar sempre por perto.

No segundo caso, a possibilidade da regulação da oferta da EI ser realizada pela iniciativa privada também necessita ser acompanhada de perto. O PNE introduziu tal questão a partir da estratégia 7.35 que visa "promover a regulação da oferta da educação básica pela iniciativa privada, de forma a garantir a qualidade e o cumprimento da função social da educação" (BRASIL, 2014, p. 19).

Para a promoção de tal regulação da oferta da educação básica, estados e municípios têm, em muitos casos, repassado essa oferta educacional para o setor privado, com ou sem fins lucrativos, o que vem sendo identificado e analisado por vários pesquisadores (ADRIÃO; PERONI, 2010; ADRIÃO et al., 2012; BALL, 2012; BALL; OLMEDO, 2013; PERONI, 2013; 2016; PERONI; COMERLATTO, 2017, entre outros).

Pesquisadores compreendem tais parcerias como parte de uma nova ordem mundial que busca a modernização da arquitetura do estado e de seus serviços. Um processo que envolve, entre outras questões, a contratação e a execução de serviços estatais por empresas privadas, por consultores que realizam pesquisas e sinalizam novas políticas, por atividades filantrópicas na área da educação, por parcerias público-privadas, que visam solucionar os problemas sociais 
e educacionais persistentes. Como situou Ball (2013, p. 177) "novas vozes e interesses são representados no processo político, e novos nós de poder e influência são construídos e fortalecidos."

Essas parcerias público-privadas Ball (2012) denominou de "Nova Filantropia", em que no centro está a ideia de doação, de auxílio gratuito e de caridade, revestida e camuflada, de fato, por um modelo comercial de investimentos. Esses novos filantropos (muitas vezes fundações) objetivam tornar visíveis e verificáveis os resultados de seus investimentos em termos de dinheiro, tempo e outros recursos tecnológicos.

Nesse processo, empresas que atuam como parceiras se apresentam como agências de credibilidade na esfera pública. Elas mesmas, muitas vezes, não possuem objetivos relacionados ao lucro e são nomeadas entidades privadas sem fins lucrativos. Todavia, por meio do marketing, elas promovem o nome da companhia, visando aumentar suas vendas e legitimando o nome do empresariado na sociedade e nos meios educacionais.

\section{A Região do Grande ABC}

O ABC Paulista, como é conhecido, é uma região onde sete cidades estão localizadas: Santo André, São Bernardo do Campo, São Caetano do Sul, Diadema, Mauá, Ribeirão Pires e Rio Grande da Serra. A área tem uma dimensão de $635 \mathrm{~km}^{2}$ de extensão com uma população de, aproximadamente, 2,7 milhões de habitantes (IBGE, 2016).

O Quadro 1 revela algumas características demográficas da região:

Quadro 1 - Características demográficas das cidades

\begin{tabular}{|c|c|c|c|c|c|c|c|}
\hline Municípios & $\begin{array}{c}\text { Santo } \\
\text { André }\end{array}$ & $\begin{array}{c}\text { São } \\
\text { Bernardo }\end{array}$ & $\begin{array}{c}\text { São } \\
\text { Caetano }\end{array}$ & Diadema & Mauá & $\begin{array}{c}\text { Ribeirão } \\
\text { Pires }\end{array}$ & $\begin{array}{c}\text { Rio } \\
\text { Grande }\end{array}$ \\
\hline $\begin{array}{c}\text { População } \\
\text { Estimada } \\
\text { (2016) }\end{array}$ & 712.749 & 822.242 & 158.825 & 415.180 & 457.696 & 121.130 & 48.861 \\
\hline $\begin{array}{c}\text { Área } \\
\text { territorial } \\
\text { Km2 (2015) }\end{array}$ & 175.782 & 409.532 & 15.331 & 30.732 & 61.909 & 99.075 & 36.341 \\
\hline PIB (milhões) & 17.664 .718 & 36.337 .338 & 11.762 .744 & 11.786 .624 & 7.633 .782 & 1.978 .256 & 529.413 \\
\hline IDHM 2010 & 0,815 & 0,805 & 0,862 & 0,757 & 0,766 & 0,784 & 0,749 \\
\hline
\end{tabular}

Fonte: Autores (2016).

Desse conjunto de cidades, São Caetano obteve, em 2000 e 2010, o maior Índice de Desenvolvimento Humano Municipal do Brasil (IDH-M). A região, no entanto, apesar de ser rica ainda possui, aproximadamente, 300 mil pessoas no nível de pobreza (GARCIA; PREARO, 2016). 
O Quadro 2 mostra alguns dados das escolas e das matrículas de Educação Infantil:

Quadro 2 - Dados das escolas e matrículas (escolas públicas e privadas) - 2020

\begin{tabular}{|c|c|c|c|}
\hline Município & Escolas & $\begin{array}{c}\text { Matrículas em } \\
\text { Creche }\end{array}$ & $\begin{array}{c}\text { Matrículas em } \\
\text { Pré-escolas }\end{array}$ \\
\hline Santo André & 272 & 14.847 & 15.935 \\
\hline São Bernardo & 273 & 20.282 & 20.924 \\
\hline São Caetano & 61 & 4.183 & 3.455 \\
\hline Diadema & 101 & 8.415 & 9.847 \\
\hline Mauá & 104 & 8.210 & 10.018 \\
\hline Ribeirão Pires & 44 & 2.215 & 2.516 \\
\hline Rio Grande da Serra & 13 & 857 & 1.179 \\
\hline Total & 868 & 51.620 & 63.874 \\
\hline
\end{tabular}

Fonte: Censo Escolar/INEP 2020 - Elaboração dos Autores.

A região possuía, em 2017, 846 escolas públicas e privadas de Educação Infantil. Um total de 56.760 matrículas, em creches e 64.520, em pré-escolas. A maior concentração das matrículas situava-se em São Bernardo do Campo.

\section{Percurso metodológico}

Neste estudo realizamos uma avaliação dos Planos Municipais de Educação dos municípios do grande $\mathrm{ABC}$, uma das regiões mais ricas do Brasil, para compreender como os municípios planejaram as melhorias para a Educação Infantil no contexto local.

A avaliação foi centrada nos objetivos (MUGNOL; GISI, 2012), nesse caso, nas metas e nas estratégias dos Planos Municipais de Educação, dos municípios da região do grande $\mathrm{ABC}$, a partir de um viés de análise com referências pedagógicas (KRAMER; NUNES; CORSINO, 2011; SILVA; PEREZ, 2010; TEBET, ABRAMOWICZ, 2010; GARCIA; GUARRIDO; MARCONI, 2017, entre outros) e sociológicas (ADRIÃO; PERONI, 2010; ADRIÃO et al, 2012; BALL, 2012; BALL; OLMEDO, 2013; PERONI, 2013; 2016; PERONI; COMERLATTO, 2017, entre outros).

A região do grande $\mathrm{ABC}$ foi selecionada por ter altos índices socioeconômicos e educacionais e se constituir em uma das mais ricas do Brasil. No entanto, ela ainda apresenta um alto quadro de desigualdade social (GARCIA; PREARO, 2016).

Neste estudo, utilizou-se a análise documental, a qual indica que o documento escrito é uma fonte valiosa para compreender, entre outras, a área de educação, em geral, e as políticas educacionais, em particular. Para Cellard (2008, p. 295), o documento é uma referência “insubstituível em qualquer reconstituição referente a um passado relativamente distante, pois não é raro que ele represente a quase totalidade dos vestígios da atividade humana em 
determinadas épocas." O documento possibilita interpretar e recriar entendimentos sobre a história, a cultura, a evolução dos grupos e dos indivíduos, das normas e das leis, entre outros.

Foram analisadas as seguintes Leis: em Santo André a Lei n. 9.723, de 20 de agosto de 2015; em São Bernardo, a Lei n. 6.447, 28 de dezembro de 2015; em São Caetano, a Lei n. 5.316, de 18 de junho de 2015; em Diadema, a Lei n. 3584, 12 de abril de 2016; em Mauá, a Lei n. 5.097, 16 de outubro de 2015; em Ribeirão Pires, a Lei n. 5.995, 30 de junho de 2015; em Rio Grande da Serra, a Lei n. 2.130, de 30 de junho de 2015.

A análise recaiu, sobretudo, sobre a meta 1 do PNE (2014-2024) que trata da EI e suas respectivas estratégias. Foram analisadas: a) a meta 1 da Educação Infantil, e b) todas as estratégias (127) dos planos dos municípios do grande ABC. Todavia, também foram analisadas algumas estratégias da meta 7 , por estarem atreladas à qualidade da educação básica e da Educação Infantil.

Para as análises das metas e de suas estratégias foram usadas as indicações da análise de conteúdo (BARDIN, 2006). Essa apreciação objetiva decifrar os documentos e [...] "compreender criticamente o sentido das comunicações, seu conteúdo manifesto ou latente, as significações explícitas ou ocultas" (CHIZZOTTI, 2006, p. 98).

\section{Resultados e discussão}

Os municípios apresentaram um total de 127 estratégias, na meta 1, propondo melhorias para a EI para os próximos dez anos, contados a partir da publicação de seus PME. Em geral, as estratégias são muito similares e muitas repetidas, retiradas do PNE. Outras apresentaram caráter muito superficial, como já sinalizado em outros estudos (GARCIA et al., 2018). Nesse contexto, a cidade de Diadema foi aquela que apresentou o maior número de estratégias (30) e Rio Grande da Serra, o menor (9).

A despeito da superficialidade das estratégias, a aprovação dos PME, para a região do Grande $\mathrm{ABC}$, representa avanços na implementação de políticas públicas para a primeira infância e, consequentemente, para o atendimento aos anseios da sociedade local com relação à garantia de acesso, de proteção e do desenvolvimento pleno de crianças, conforme têm preconizado os debates nacionais em prol da Educação Infantil (KRAMER; NUNES; CORSINO, 2011; SILVA; PEREZ, 2010; TEBET, ABRAMOWICZ, 2010).

As estratégias encontradas nos PME foram agrupadas em dois grandes grupos. Aquelas que estão alinhadas com as melhorias da Educação Infantil e aquelas que vão ao encontro dos interesses mercadológicos. 


\section{Estratégias alinhadas com a melhoria da educação infantil}

Todas os municípios, exceto Rio Grande da Serra, pretendem enriquecer o currículo da EI, a partir vários programas (educação ambiental, educação para a paz) e alinhar as diretrizes em todas as escolas. Diadema deseja alinhar o currículo da Educação Infantil ao do $1^{\circ}$ ano do Ensino Fundamental, assegurando aos alunos um percurso escolar harmonioso.

Com exceção de Santo André e de Rio Grande, as demais cidades do Grande ABC objetivam garantir que seja inferior a $10 \%$ a diferença entre as taxas de frequência das crianças de creches oriundas do quinto de renda familiar per capita mais elevada e as do quinto mais baixo. Para tal, esses municípios pretendem ampliar a oferta e reafirmam conceber a educação como direito da criança e não somente como uma necessidade da família.

Os municípios almejam atuar na preservação das especificidades da Educação Infantil, na organização dos sistemas e das redes escolares, sejam elas públicas ou privadas. Dessa forma, pretendem assegurar atendimento da criança em escolas que atendam os parâmetros nacionais de qualidade.

Todas as cidades investigadas pretendem expandir suas redes de ensino. Nesse caso, idealizam realizar a expansão, em regime de colaboração, entre a União e o Estado de São Paulo. Para tal, utilizar-se-ão do padrão nacional de qualidade em infraestrutura, em recursos pedagógicos e em formação de recursos humanos. Idealizam também adotar as regras de acessibilidade e utilizar planejamento para construção, reestruturação e manutenção de escolas municipais.

De fato, trata-se de uma estratégia relevante, considerando que estudos revelaram que a infraestrutura (instalações, equipamentos, materiais, entre outros) "abriga, sustenta e possibilita a criação e a organização de ambientes escolares de aprendizagem para o desenvolvimento da criança na Educação Infantil” (GARCIA; GUARRIDO; MARCONI, 2017, p. 151).

A infraestrutura torna-se ainda mais importante, de acordo com o mesmo estudo, considerando que na região do grande $\mathrm{ABC}$, entre os municípios, ela é bem diferenciada. Há grande variabilidade entre as escolas e, o mais agravante, dentro do mesmo município, indicando que crianças, de uma mesma cidade, têm acesso e oportunidades de aprendizagem, a partir da construção e organização de ambiente de aprendizagens, diferentes. (GARCIA; GUARRIDO; MARCONI, 2017, p. 151).

Melhorar a infraestrutura escolar, de fato, auxilia na luta para atenuar as desigualdades sociais, pois faz com que "crianças de nível socioeconômico mais baixo tenham acesso e 
oportunidades de utilizar e manusear materiais e equipamentos, e vivenciar situações de aprendizagem que não seriam possíveis em suas realidades sociais (contexto familiar e social)" (GARCIA et al., 2017, p. 151).

Todas as cidades do grande ABC pretendem expandir suas redes e ampliar a oferta de vagas, a partir da otimização dos espaços já existentes e com a realização de convênios com os governos Federal e Estadual. Com esse objetivo, buscam estimular o acesso à EI em tempo integral para todas as crianças e, nesse sentido, atender as Diretrizes Curriculares Nacionais para a Educação Infantil, de 2013. De fato, essa discussão sobre a ampliação da oferta para garantir o atendimento das crianças se caracteriza no primeiro desafio em relação à qualidade da EI, que está associada aos dos direitos da criança (CORRÊA, 2003).

Para subsidiar o planejamento da oferta de vagas e o atendimento da demanda manifesta, todos os municípios desejam realizar, periodicamente, em regime de colaboração com a rede privada, levantamento da demanda por creche, instituindo uma busca ativa de crianças de 0 a 5 anos de idade. Ao mesmo tempo, com exceção de Santo André, as cidades do Grande ABC pretendem criar estruturas de consulta pública para as famílias com informações acerca da demanda por vagas na EI. Com tais mecanismos visam ampliar o acesso das crianças à escola.

Essas cidades pretendem, também, promover a formação inicial e continuada de professores e funcionários, articulando parcerias com as universidades e com institutos superiores. Tal situação visa, entre outras questões, assegurar, de forma paulatina, que o atendimento da criança seja realizado por profissionais com nível superior e especialização na área de atuação, proporcionando a esses os avanços dos estudos das pesquisas ligadas ao processo de ensino-aprendizagem e às teorias educacionais.

Três cidades, São Bernardo, São Caetano e Mauá, buscam também articular, no contexto da formação, a pós-graduação, os núcleos de pesquisa e os cursos de formação de profissionais da educação para garantir a elaboração de currículos e de propostas pedagógicas inovadoras e coerentes com uma educação de qualidade social.

Tais tratativas de formação, inicial e continuada, são, de fato, premissas que buscam melhorar a qualidade da Educação Infantil, seja pela transformação do perfil docente, sendo adequado às escolas (CAMPOS, 2008), seja pelo aprimoramento profissional para melhorar a prática pedagógica (KRAMER; NUNES; CORSINO, 2005).

As cidades do grande $\mathrm{ABC}$ objetivam ampliar, em caráter complementar, programas para apoiar e orientar as famílias, as comunidades e as escolas, articulando as áreas de educação, saúde, assistência social e esportes. Nesse mesmo sentido, os municípios pretendem também fortalecer o acompanhamento e o monitoramento do acesso e da permanência das crianças na 
EI, sobretudo, daquelas crianças que possuem benefícios de programas de transferência de renda.

A implementação de projetos e programas se constitui em estratégia relevante, posto que o desenvolvimento da qualidade exige políticas públicas, programas compensatórios, projetos pedagógicos com o intuído de auxiliar a comunidade no enfrentamento de problemas locais associados à violência, às drogas, ao transporte escolar, à saúde e ao lazer, entre outros (DOURADO; OLIVEIRA; SANTOS, 2007; DOURADO; OLIVEIRA, 2009).

Garantir a oferta do atendimento educacional especializado, complementar e suplementar, às crianças com deficiência, transtornos globais do desenvolvimento e altas habilidades ou superdotação, assegurando a educação bilíngue para crianças surdas, é parte dos objetivos de todas as cidades em seus PME. Trata-se de uma estratégia pertinente, pois é necessário assegurar a oferta e, ao mesmo tempo, superar alguns desafios, tais como mudar as concepções dos professores em relação ao aluno com deficiência e melhorar a formação docente, entre outras.

\section{Estratégias alinhadas com os interesses mercadológicos da educação infantil}

Com exceção de Mauá, as cidades do grande $\mathrm{ABC}$ almejam promover a regulação da oferta da Educação Básica pela iniciativa privada de forma a garantir o acesso, a qualidade e o cumprimento da função social da educação. Tal iniciativa visa, em alguns casos, o cumprimento da EC 59/2009, que tornou a educação brasileira obrigatória dos 4 aos 17 anos.

Tal estratégia, que reproduz o que está sinalizado no Plano Nacional de Educação, apresenta consonância com as políticas neoliberais, sobretudo a questão da manutenção da mercantilização da Educação. Nesse caso, por meio de uma legislação prescritiva (Lei), mantem-se a lógica mercadológica, um contexto que motiva o desenvolvimento do setor privado, gerando e garantindo expansão quantitativa e lucro.

Essa questão da regulação da oferta pela iniciativa privada indica, em primeiro lugar, sintonia com as políticas de privatização do ensino, que poderá acontecer, por exemplo, a partir de uma política de vouchers. Em segundo, induz o pensamento de superioridade da esfera privada em relação à pública, associando à educação às necessidades do mercado de trabalho dentro de um mercado produtivo.

Nesse mesmo contexto, todas as cidades do grande ABC desejam expandir suas redes e ampliar a oferta de vagas, a partir da realização de parcerias com a colaboração de entidades sem fins lucrativos (filantrópicas). Em alguns planos municipais (São Caetano, Mauá, Diadema, 
Ribeirão Pires), essas indicações aparecem diretamente e, em outros (Santo André e São Bernardo), indiretamente, em outras estratégias.

Tais parcerias, todavia, muito provavelmente, transferirão a execução da oferta educacional para o setor privado que, distante dos objetivos de auxílio às redes de ensino, visam o aumento de seus investimentos (BALL, 2012; BALL; OLMEDO, 2013; PERONI, 2013; 2016; PERONI; COMERLATTO, 2017, entre outros). Trata-se de uma nova filantropia (BALL, 2012) que está disseminada no Brasil e presente nos documentos, legislações e projetos no Ensino Fundamental, Médio, Educação Profissional Técnica, entre outras (PERONI, 2016).

No caso da educação infantil, alvo deste presente estudo, quando ela começou a fazer parte da educação básica, começaram os avanços dessas parcerias com o setor privado. Nesse contexto, as creches, por exemplo, quando saíram da assistência social e passaram a ser de responsabilidade dos governos municipais, tiveram a oferta, em muitos casos, associada às parcerias com instituições sem fins lucrativos. No entanto, existe, como sinalizou Peroni (2016, p. 97), uma enorme inquietação com:

[...] a fragilidade e a precariedade deste atendimento, no que se refere às condições físicas do local, projeto pedagógico, remuneração e formação dos professores e a não gratuidade, com mensalidades sendo cobradas mesmo recebendo dinheiro público e de famílias muito carentes. Outro fator importante é a ausência de gestão democrática nas instituições, com critérios pouco transparentes na admissão e pagamento dos funcionários, falta de critérios para a admissão das crianças, de prestação de contas da entidade, assim como nas relações dentro das creches e da instituição dos pais e comunidade.

Pode-se compreender que essa execução da oferta pelo setor privado, com ou sem fins lucrativos, como sinalizado nos planos educacionais dos municípios, confere à Educação Infantil, em geral, e à creche, em particular, uma forma de barateamento e de precarização do ensino das crianças.

Os municípios idealizam criar, em regime de colaboração com o MEC, até o segundo ano de vigência deste PME, a avaliação da Educação Infantil para ser realizada a cada dois anos. Para tal, pretendem utilizar os parâmetros nacionais de qualidade, a fim de aferir a infraestrutura física, os recursos pedagógicos, os profissionais, as condições de gestão, a questão da acessibilidade, entre outros indicadores relevantes. Essa situação visa organizar as demandas apresentadas na avaliação para auxiliar no planejamento e na criação de políticas públicas.

Todavia, trata-se de uma estratégia descrita, em termos de redação, de forma superficial e pouco específica, que efetivamente abre espaços para outras interpretações. Como não se faz referência a essa relevância do indicador a ser construído, pode-se assumir, de fato, o desempenho do aluno como um elemento importante para a compreensão da qualidade da EI, 
tal qual ocorre no ensino fundamental e médio, por meio de avaliações em larga escala, de provas padronizadas, descontextualizas, que geram rankings e competições entre as escolas favorecendo, como situou Hagopian (2014), um grande mercado de consumo da educação.

Essas avaliações, já bem instituídas no Brasil, ainda direcionam políticas de responsabilização para docentes e escolas, produzem injustiças quanto às premiações das melhores instituições, em alguns casos, diminuem a autonomia dos professores, alteram a forma como os conteúdos são ensinados, podem estreitar o currículo, entre outras questões.

A fim de detalhar ainda mais essa questão, alguns municípios (Ribeirão Pires) pretendem "implantar na Rede Municipal de ensino, um sistema de avaliação de desenvolvimento infantil de zero a cinco anos de maneira que possa contribuir para a construção de projeto pedagógico para as crianças e sua evolução em período esperado para as idades". (RIBEIRÃO PIRES, 2015).

Observa-se, novamente, uma estratégia, com um tipo de redação que não indica se o sistema será construído baseado nas tradições de avaliação e de monitoramento da EI brasileira cujas diretrizes estão presentes na LDBEN/96 (art. 31), nas Diretrizes Curriculares Nacionais para a Educação Infantil (2009), no Plano Nacional da Primeira Infância (2011 - 2022), no Plano Nacional de Educação (2014-2024), nos Parâmetros Nacionais de Qualidade para a Educação Infantil, 2006, nos Indicadores da Qualidade na Educação Infantil, 2009 e nos Referenciais Curriculares Nacionais, 2013. Esses documentos preconizam o acompanhamento da criança por meio da observação, do registro, da análise individual dos comportamentos e das atitudes, das produções em situações variadas, revelando particularidades próprias desse nível de ensino.

Com essa ausência de especificidade, outras interpretações poderão atrelar à avaliação da EI ao desempenho e aos resultados. De fato, como indicou Didonet (2012), a Educação Infantil não está à margem da avalanche de avaliação que existe no Brasil.

Por fim, registra-se que a cidade de Diadema circunscreveu o maior número de estratégias. Algumas delas somente constavam em seu PME. Entre essas estratégias, o município pretende ampliar a equipe de manutenção e reparos nas escolas; assegurar o pagamento do piso salarial aos profissionais; ampliar a equipe multiprofissional de atendimento das demandas psicossociais e formativas; assegurar que as escolas tenham seu Plano de Gestão em consonância com as Diretrizes Curriculares Nacionais e Municipal cuja construção deverá contar com a participação dos profissionais da escola, do conselho e da comunidade escolar; criar e fomentar programas de conscientização ambiental; garantir à população negra e indígena o ingresso, permanência e o sucesso na educação escolar; valorizar o patrimônio histórico 
cultural afro-brasileiro e indígena; criar ações de combate e prevenção a situações de racismo, qualquer tipo de discriminação (sexismo, gênero, religião e bullying), reconhecendo a diversidade, que deve ser entendida como a pluralidade cultural, étnico-racial, regional, linguística, religiosa, biológica, social, política; assegurar aquisições de materiais didáticos que contemplem a diversidade; promover formações específicas para subsidiar os profissionais nas temáticas relacionadas à Diversidade.

Dado o volume de informações encontradas nos PME da região investigada, o Quadro 3 sintetiza os principais achados da pesquisa.

Quadro 3 - Síntese dos resultados

\begin{tabular}{|c|c|c|c|c|c|c|c|}
\hline Grupo & Categorias & \multicolumn{6}{|c|}{ Estratégias encontradas nos planos } \\
\hline \multirow{5}{*}{$\begin{array}{l}\text { Grupo } 1 \text { - } \\
\text { alinhadas } \\
\text { com a } \\
\text { melhoria da } \\
\text { EI }\end{array}$} & Infraestrutura & Expansão física & \multicolumn{4}{|c|}{$\begin{array}{l}\text { Expansão da oferta de } \\
\text { vagas }\end{array}$} & $\begin{array}{l}\text { Ampliação do acesso à } \\
\text { Escola de tempo integral }\end{array}$ \\
\hline & $\begin{array}{l}\text { Desenvolvimento } \\
\text { de } \\
\text { Programas }\end{array}$ & \multicolumn{6}{|c|}{$\begin{array}{l}\text { Implementar, em caráter complementar, programas de orientação e apoio } \\
\text { às famílias, por meio da articulação das áreas de educação, saúde e } \\
\text { assistência social, com foco no desenvolvimento integral das crianças/ }\end{array}$} \\
\hline & Famílias & \multicolumn{3}{|c|}{$\begin{array}{l}\text { Programas de orientação e apo } \\
\text { às famílias }\end{array}$} & & \multicolumn{2}{|c|}{$\begin{array}{l}\text { Ampliar formas de participação das } \\
\text { famílias e comunidade, visando à } \\
\text { ação articulada de atendimento à } \\
\text { criança }\end{array}$} \\
\hline & Inclusão & \multicolumn{6}{|c|}{$\begin{array}{l}\text { Garantir a oferta do atendimento educacional especializado complementar } \\
\text { e suplementar as crianças com deficiência, transtornos globais do } \\
\text { desenvolvimento e altas habilidades ou superdotação, assegurando a } \\
\text { educação bilíngue para crianças surdas. }\end{array}$} \\
\hline & Professores & \multicolumn{3}{|c|}{$\begin{array}{l}\text { Formação para garantir o } \\
\text { atendimento das crianças por } \\
\text { profissionais com Ensino }\end{array}$} & \multicolumn{3}{|c|}{$\begin{array}{l}\text { Formação para garantir a elaboração de } \\
\text { currículos e propostas pedagógicas que } \\
\text { incorporem os avanços de pesquisas } \\
\text { ligadas ao processo de ensino- } \\
\text { aprendizagem e às teorias educacionais }\end{array}$} \\
\hline \multirow[b]{2}{*}{$\begin{array}{l}\text { Grupo } 2- \\
\text { alinhadas } \\
\text { com os } \\
\text { interesses } \\
\text { privados }\end{array}$} & $\begin{array}{l}\text { Planejamento da } \\
\text { oferta }\end{array}$ & \multicolumn{2}{|c|}{$\begin{array}{l}\text { Promover a regulação } \\
\text { da oferta de ensino da } \\
\text { educação básica pela } \\
\text { iniciativa privada }\end{array}$} & \multicolumn{4}{|c|}{$\begin{array}{l}\text { Expandir as redes de ensino e ampliar a oferta } \\
\text { de vagas, a partir da realização de parcerias } \\
\text { com a colaboração de entidades sem fins } \\
\text { lucrativos (filantrópicas) }\end{array}$} \\
\hline & Avaliação & $\begin{array}{l}\text { Criar a avaliação } \\
\text { da Educação } \\
\text { Infantil com base } \\
\text { em parâmetros } \\
\text { nacionais de } \\
\text { qualidade }\end{array}$ & \multicolumn{4}{|c|}{$\begin{array}{l}\text { Fortalecer o } \\
\text { acompanhamento e o } \\
\text { monitoramento do } \\
\text { acesso e da } \\
\text { permanência das } \\
\text { crianças na Educação } \\
\text { Infantil }\end{array}$} & $\begin{array}{l}\text { Aferir na avaliação da } \\
\text { Educação Infantil a } \\
\text { infraestrutura física, o } \\
\text { quadro de pessoal, as } \\
\text { condições de gestão, os } \\
\text { recursos pedagógicos, a } \\
\text { situação de acessibilidade, } \\
\text { entre outros indicadores } \\
\text { relevantes }\end{array}$ \\
\hline
\end{tabular}

Fonte: Elaboracão dos autores.

\section{Considerações finais}

A avaliação sobre os PME dos municípios da região do grande $\mathrm{ABC}$ apontou, inicialmente, para similaridades, repetições, a partir do Plano Nacional de Educação, e para 
certa superficialidade na maioria das estratégias, carecendo, nesse sentido, de maiores especificidades, tal como prazo para a execução.

A despeito da premissa de que o PME deve estar alinhado ao PNE, bem como ao Plano Estadual de Educação, existia a expectativa de que suas metas e estratégias não fossem superficiais em decorrência dos demais planos. Esperava-se, inclusive, que a construção dos PME mobilizasse todos os segmentos da sociedade. Não obstante, considerando-se a abordagem adotada pelos municípios investigados acerca das estratégias de seus planos, inferese que esse documento pode se constituir muito mais no atendimento às determinações emanadas do Governo Federal do que em políticas efetivas para a educação municipal em si.

Contudo, apesar dessas fragilidades, é oportuno destacar que foram identificados dois grupos de estratégias inseridas nos PNE. No primeiro, estão aquelas alinhadas com as melhorias da Educação Infantil e, no segundo, outras voltadas para manter sua mercantilização.

As estratégias do primeiro grupo buscam melhorar a infraestrutura escolar; o atendimentos de alunos de inclusão; expandir as redes de ensino, ampliar oferta de vagas (para garantir o atendimento das crianças); realizar levantamento da demanda por creche, instituindo uma busca ativa de crianças de 0 a 5 anos de idade por meio da criação de um sistema consulta pública que subsidiará tanto os municípios no atendimento da demanda escolar quanto às famílias que buscam vagas em creches e pré-escolas; promover formação inicial e continuada de profissionais da educação; ampliar programas para apoiar e orientar as famílias, entre outras.

Por sua vez, as estratégias do segundo grupo estão associadas à questão da promoção da regulação da oferta da educação básica pela iniciativa privada, a partir da possibilidade de parcerias público-privadas, e a criação da avaliação da Educação Infantil, que não possui definições claras nos Planos Municipais de Educação.

Esse segundo grupo de estratégias necessita ser acompanhado de perto por especialistas, gestores, professores e comunidade escolar para que não se transforme em processos já conhecidos e muito bem estabelecidos no ensino fundamental e médio: a questão dos testes, resultados, rankings, premiações, punições e vendas de material por empresas privadas, entre outros.

Embora essa análise não se constitua em uma ação efetiva de monitoramento dos PME, os achados desta pesquisa deixam pistas que poderão subsidiar os munícipes e, principalmente, os profissionais da educação no processo de avaliação dos planos.

Ademais, o acompanhamento dos PME se constitui em um processo importante para que a sociedade possa atuar, de forma efetiva, em seu processo de implementação, bem como estar atenta a eventuais estratégias que não atendam a seus interesses. Nesse caso em específico, 
poderá tentar impedir que a política por resultados, entendida como sinônimo de qualidade, seja implantada na Educação Infantil, pois é sabido que ela é perniciosa, na medida em que induz as redes de ensino a buscar melhores resultados, ao invés da qualidade e a equidade educativa.

\section{Referências}

ADRIAO, Theresa; PERONI, Vera Maria Vidal. Análise das consequências de parcerias firmadas entre os municípios brasileiros e a Fundação Ayrton Senna. Relatório Parcial de Pesquisa, 2010. Mimeo.

ADRIAO, Theresa; GARCIA, Teise; BORGHI, Raquel; ARELARO, Lisete. As parcerias entre prefeituras paulistas e o setor privado na política educacional: expressão de simbiose? Educ. Soc. v. 33, n. 119, 2012.

BALL, Stephen J. Global Educacion INC. New Plicy Networks and the neo-liberal imaginary. Routledge, London, 2012.

BALL, Stephen. OLMEDO. Antônio. A "nova” filantropia, o capitalismo social e as redes de políticas globais em educação. In: PERONI, V. (org.). Redefinições das fronteiras entre o público e o privado: implicações para a democratização da educação. Brasília: Liber Livro, 2013.

BARDIN, Laurence. Análise de conteúdo. Lisboa: Edições 70. 2006.

BRASIL. Estatuto da Criança e do Adolescente. Lei n. 8.069, de 13 de julho de 1990.

BRASIL. Política Nacional de Educação Infantil. Ministério da Educação. Secretaria de Educação Fundamental. Brasília: MEC/SEF/COEDI, 1994.

BRASIL. Diretrizes Curriculares Nacionais para a Educação Infantil. Ministério da Educação. Secretaria de Educação Fundamental. Brasília: MEC/SEF/COEDI, 1994. BRASIL. Lei $n^{\circ}$ 9.394, de 20 de dezembro de 1996. Estabelece as diretrizes e bases da educação nacional. Brasília, DF, dez 1996. Disponível em:

http://www.planalto.gov.br/ccivil_03/leis/19394.htm. Acesso em: 06 mai. 2018.

BRASIL. Referencial curricular nacional para a educação infantil. Ministério da Educação e do Desporto, Secretaria de Educação Fundamental. - Brasília: MEC/SEF, 1998. Disponível em: http://portal.mec.gov.br/seb/arquivos/pdf/rcnei_vol1.pdf. Acesso em: 06 ago. 2018.

BRASIL. Parâmetros nacionais de qualidade para a educação infantil. Ministério da Educação. Secretaria de Educação Básica. Brasília: MEC/SEF, 2006.

BRASIL. Plano Nacional de Educação. Lei 13.005. Ministério da Educação. Secretaria de Educação Básica. Brasília: MEC/SEF, 2014.

BRASIL. Ministério da Educação. Conselho Nacional de Educação. Resolução CNE/ CEB $n^{o}$ 5 de 17 de dezembro de 2009. Fixa as Diretrizes Curriculares Nacionais para a Educação Infantil. Disponível em: www.mec.gov.br. Acesso em: 06 mai. 2018. 
CAMPOS, Maria Malta. Educar crianças pequenas. Em busca de um novo perfil de professor. Revista Retratos da Escola, Brasília, v. 2, n. 2-3, p. 121-131, jan./dez. 2008.

CELLARD, André. A análise documental. In: POUPART, Jean et al. A pesquisa qualitativa: enfoques epistemológicos e metodológicos. Petrópolis: Vozes, 2008.

Chizzotti, Antonio. Pesquisa em ciências humanas e sociais. São Paulo: Cortez. 2006.

CORRÊA, Bianca Cristina. Considerações sobre qualidade na educação infantil. Cadernos de Pesquisa, n. 119, p. 85 - 112, julho 2003.

COSTA, Frederico Lustosa; CASTANHAR, Jose. Cesar. Avaliação de programas públicos: desafios conceituais e metodológicos. Revista de Administração Pública, Rio de Janeiro, v. 37, n. 5, p. 969- 992, 2003.

DIADEMA. Lei $n^{o} 3.584$, de 12 de abril de 2016. Aprova o Plano Municipal de Educação do Município de Diadema. Diadema,16 abr. 2016. Disponível em: https://bit.ly/2rd5kV5. Acesso em: 25 set. 2016.

DIDONET, Vital. A avaliação na e da educação infantil. São Paulo: Ministério Público do Estado de São Paulo, 2012.

DOURADO, Luiz Fernando; OLIVEIRA, João Ferreira; SANTOS, Catarina de Almeida. A qualidade da educação: conceitos e definições. Série Documental: Textos para Discussão, Brasília, DF, v. 24, n. 22, p. 5-34, 2007.

DOURADO, Luiz Fernando; OLIVEIRA, João Ferreira. Qualidade da educação: perspectivas e desafios. Cad. Cedes, Campinas v. 29, n. 78, p. 201-215, 2009.

GARCIA, Paulo. Sergio; FAZIO, Xavier; PANNIZZON, Debra; BIZZO, Nélio. Austrália, Brasil e Canadá: impacto das avaliações no ensino de ciências. Estudos em Avaliação Educacional (IMPRESSO), v. 1, p. 1-34, 2018 b.

GARCIA, Paulo Sérgio; BIZZO, Nélio. O Processo de Elaboração dos Planos Municipais de Educação na Região do Grande ABC. Educação e Realidade Edição eletrônica, v. 43, p. 337$362,2018$.

GARCIA, Paulo Sérgio; MIRANDA, Nonato. Análise da qualidade da educação a partir do Planos Municipais de Educação. In: CONGRESO IBEROAMERICANO DE POLÍTICA E ADMINISTRACIÓN DE LA EDUCACIÓN, 6., 2018, Lheida - Espanha. Anais [...]., 2018. v. 3. p. $98-103$.

GARCIA, Paulo Sergio; GARRIDO, Érica Loureiro; MARCONI, Juliana. Um estudo sobre da infraestrutura da educação infantil da região do grande ABC Paulista. HOLOS (Natal. Online), v. 1, p. 139-154, 2017.

GARCIA, Paulo Sergio.; PREARO, Leandro Campi. Avaliação de Educação Escolar no Grande ABC Paulista - Múltiplas análises. 1. ed. São Paulo: UNI, 2016. v. 2. 164p.

Instituto Nacional de Estudos e Pesquisas (Inep). Censo da Educação Básica, 2020. 
HAGOPIAN, Jesse (Ed.). More than a score: the new uprising against high-stakes testing. Chicago: Haymarket Books, 2014.

IBGE. Instituto Brasileiro de Geografia e Estatística. Pesquisa Nacional por Amostra de Domicílios: Síntese de indicadores de 2016 - PNAD. Rio de Janeiro, 2016.

KRAMER, Sonia (Org.). Profissionais de educação infantil: gestão e formação. São Paulo: Ática, 2005.

KRAMER, Sonia; NUNES, Maria Fernandes R.; CORSINO, P. Infância e crianças de 6 anos: desafios das transições na educação infantil e no ensino fundamental. Educação e Pesquisa, São Paulo, v.37, n.1, p. 69-85, jan./abr. 2011.

LIMA, JR., OLAVO, B.; SILVA, Ana de Abreu; LEITE, Maria Claudia. Intervenção planejada na realidade social: escopo e limites da pesquisa de avaliação. Rio de Janeiro, IUPERJ, 1978.

MANTOAN, Maria Teresa Eglér. Inclusão escolar: o que é? por quê? como fazer? São Paulo: Moderna, 2003.

MAUÁ. Lei n ${ }^{\circ} 5.097$, de 16 de outubro de 2015. Aprova o Plano Municipal de Educação do Município de Mauá. Diário Oficial. Mauá, 20 out. 2015.

Avaliação de políticas públicas educacionais: os resultados do Prouni. In: ANPED SUL, 9., Caxias do Sul, 2012. Anais... p. 1-16. Disponível em: http://www.ucs.br/etc/conferencias/index.php/anpedsul/9anpedsul/ paper/viewFile/2022/970 Acesso em: 15 out. 2013.

PERONI, Vera Maria Vidal. (org.). Redefinições das fronteiras entre o público e o privado: implicações para a democratização da educação. Brasília, Liber Livro, 2013.

PERONI, Vera Maria Vidal. As Implicações da relação público-privada para a democratização da educação no Brasil. Tese (promoção a Professor Titular da Carreira do Magistério Superior), UFRGS. 2016.

PERONI, Vera Maria Vidal. COMERLATTO, Luciani Paz. Parceria Público-Privada e a Gestão da Educação: o Programa Gestão Nota 10 do Instituto Ayrton Senna. Perspectiva, Florianópolis, v. 35, n. 1, p. 113-133, jan./mar. 2017.

RIBEIRÃO PIRES. Lei n. 5.995, DE 30 de junho de 2015. Aprova o Plano Municipal de Educação. Diário Oficial. Ribeirão Pires, 30 jun. 2015.

RIO GRANDE DA SERRA. Lei n 2.130, de 30 junho de 2015. Aprova o Plano Municipal de Educação. Diário Oficial. Rio Grande, 30 jun. 2015.

SANTO ANDRÉ. Lei no 9.723, de 20 de agosto de 2015. Aprova o Plano Municipal de Educação do Município de Santo André. Diário do Grande $A B C n^{\circ} 16219$, Santo André, 23 julho 2015. 
SÃO BERNARDO. Lei $\mathrm{n}^{\circ}$ 6.447, de 28 de dezembro de 2015. Aprova o Plano Municipal de Educação do Município de São Bernardo. Leis Municipais. São Bernardo, 28 dez 2015. Disponível em: https://bit.ly/2FzG9jR. Acesso em: 18 fev. 2016.

SÃO CAETANO DO SUL (SCS). Lei n 5.316, de 18 de junho de 2015. Aprova o Plano Municipal de Educação do Município de São Caetano. São Caetano, 18 de jun 2015. Disponível em: www.saocaetanodosul.sp.gov.br. Acesso em: 22 set. 2016.

TEBET, Gabriela Guarnieri de Campos; ABRAMOWICZ, Anete. Creches, educação infantil e políticas públicas municipais: um olhar sobre a cidade de São Carlos - Brasil. Políticas Educativas, Porto Alegre, v. 3, n.2, p.25-39, 2010. 